\title{
Magnetic Resonance Imaging under Sedation in Pediatric Patients: A Single-Institution Experience
}

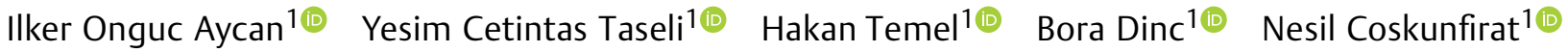 \\ Suat Sanli ${ }^{10}$ \\ ${ }^{1}$ Department of Anesthesiology and Reanimation, Akdeniz University \\ Medical Faculty, Antalya, Turkey \\ Address for correspondence Yesim Cetintas Taseli, MD, Department \\ of Anesthesiology and Reanimation, Akdeniz University Medical \\ Faculty, 07070 Antalya, Turkey (e-mail: yesimcetintas@yahoo.com).
}

J Child Sci 2021;11:e185-e192.

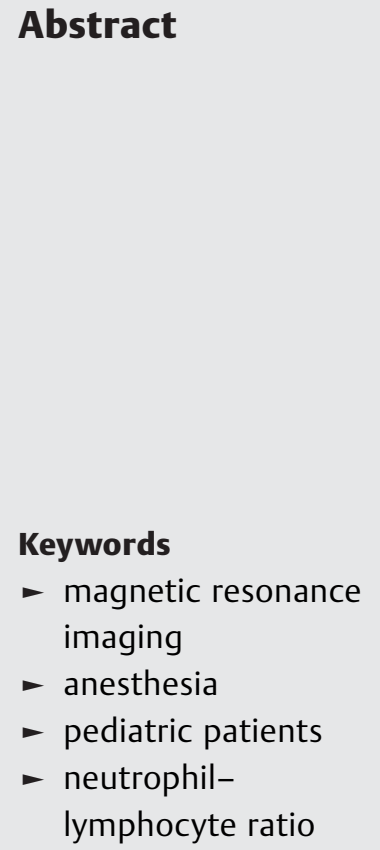

Magnetic resonance imaging (MRI) scans for children are a challenge for anesthesiologists since the child must be sedated enough to stand still. But anesthetic drugs used for sedation might have serious side effects and monitorization resources and accessibility to the patient during MRI scan is limited. We retrospectively examined 977 pediatric patients' files who had MRI scans in our hospital. We observed that children received one of the four combinations of anesthetic drugs: group 1 received midazolam, propofol, and ketamine; group 2 received midazolam and ketamine; group 3 received midazolam and thiopental; and group 4 received midazolam and propofol combination for sedation. The patients in group 1 had significantly higher vomiting rates than the patients in group $4(p=0.005)$. We observed bronchospasm in patients in group $1(p=0.006)$ and group $3(p=0.001)$, more than in patients in group 4. Nausea and vomiting ratios were lower in group 4 . In patients with nausea and vomiting within a week after the procedure, statistically significant lower neutrophil-lymphocyte ratio values $(p=0.012)$ were observed. All four anesthetic combinations used in the trial provided safe anesthesia for the children, during the MRI scan. The anesthetic choice must be made according to the procedure time and patient's comorbidities. In this trial, we observed minimum side effects with midazolam and propofol combination.

\section{Introduction}

The frequency of magnetic resonance imaging (MRI) scans in pediatric patients has increased in recent years. ${ }^{1}$ The MRI has become the preferred diagnostic procedure for many conditions because it is a noninvasive and radiation-free diagnostic procedure.

An MRI scan can take $\sim 10$ to 30 minutes. It is quite noisy, and the patient is moved into a narrow cylinder with limited access. $^{2}$ The patient must lie motionless inside a tunnel-like magnetic coil during the MRI scan. ${ }^{3}$ Several factors related to MRI can cause fear, agitation, and anxiety in patients,

received

January 7, 2021

accepted after revision

May 7, 2021
DOI https://doi.org/

10.1055/s-0041-1731335.

ISSN 2474-5871. including an unfamiliar environment, the presence of unknown staff, and lengthy scan times. ${ }^{4}$

There are a variety of drugs available for sedation for those undergoing MRI. In this study, four drug groups (propofol, ketamine, midazolam, and thiopental) were analyzed retrospectively. These anesthetic agents are widely used for sedation, but they all have their advantages and disadvantages. Unfortunately, there is not a perfect anesthetic agent, and some complications observed after sedation can be related to the patient's primary disease. In this study, we aimed to determine the relationship between sedative agents and complications after the sedation. Also, we aimed (c) 2021. The Author(s).

This is an open access article published by Thieme under the terms of the Creative Commons Attribution License, permitting unrestricted use, distribution, and reproduction so long as the original work is properly cited. (https://creativecommons.org/licenses/by/4.0/)

Georg Thieme Verlag KG, Rüdigerstraße 14, 70469 Stuttgart, Germany 
Table 1 Anesthetic drugs

\begin{tabular}{|l|l|l|l|l|}
\hline & Group 1 (mean \pm SD) & Group 2 (mean \pm SD) & Group 3 (mean \pm SD) & Group 4 (mean \pm SD) \\
\hline Propofol $\left(\mathrm{mg} \cdot \mathrm{kg}^{-1}\right)$ & $1.43 \pm 0.56$ & 0 & 0 & $1.90 \pm 0.83$ \\
\hline Ketamine $\left(\mathrm{mg} \cdot \mathrm{kg}^{-1}\right)$ & $1.45 \pm 0.63$ & $1.92 \pm 0.96$ & 0 & 0 \\
\hline Midazolam $\left(\mathrm{mg} \cdot \mathrm{kg}^{-1}\right)$ & $0.07 \pm 0.03$ & $0.08 \pm 0.05$ & $0.08 \pm 0.03$ & $0.08 \pm 0.03$ \\
\hline Thiopental $\left(\mathrm{mg} \cdot \mathrm{kg}^{-1}\right)$ & 0 & 0 & $4.25 \pm 1.30$ & 0 \\
\hline
\end{tabular}

Abbreviation: SD, standard deviation.

Note: Anesthetic drugs used in each group were given as mean \pm SD and $\mathrm{mg} / \mathrm{kg}^{-1}$. Values are given as mean \pm SD.

to determine the drug group that would provide optimum image quality during MRI and at the same time create minimal complications. Ketamine dissociates the thalamus from the limbic cortex, which causes dissociative anesthesia. Clinically, the patient appears conscious but unable to respond. The ventilatory drive is minimally affected. Ketamine also has analgesic and amnesic effects, but it increases cerebral oxygen consumption, cerebral blood flow, and intracranial pressure. ${ }^{5}$ Midazolam is a benzodiazepine that can be administered orally, intramuscularly, and intravenously to provide premedication, sedation, or, less commonly, to induce general anesthesia. The United States Food and Drug Administration has not approved oral administration of midazolam. Benzodiazepines have minimal cardiovascular depressant effects. Moreover, small doses of midazolam can result in respiratory arrest. ${ }^{5}$ Thiopental is a barbiturate with hypnotic and anticonvulsant effects. Thiopental also decreases intracranial pressure that also has hemodynamic and respiratory depression effects. ${ }^{5}$ In recent years, propofol has become the first choice for sedation, but it can cause respiratory depression and arterial hypotension. However, propofol also has some advantages such as short duration of action and some antiemetic properties. Therefore, it is clear that the anesthetic drug of choice must be chosen according to the comorbidities of the patient. For example, ketamine does not cause respiratory depression, but we cannot use it in a patient with elevated intracranial pressure.

\section{Materials and Methods}

After approval by the Institutional Ethics Committee (date:28/05/2020 and issue number: KAEK-354), we performed a retrospective observation of medical records of patients aged between 1 month and 18 years old with an American Society of Anesthesiologists (ASA) Physical Status Classification of 1 to 3, who received sedation for MRI between February 1, 2017, and February 1, 2018, at Akdeniz University Hospital. We observed that children received one of the four combinations of anesthetic drugs; group 1 received midazolam (Sedazolam, Monem Farma, Ankara, Turkey), propofol (Lipuro, Braun, Melsungen Germany), and ketamine (Ketax Vem Medikal, Istanbul, Turkey); group 2 received midazolam and ketamine; group 3 received midazolam and thiopental (Pental Sodium, Ibrahim Ethem, Istanbul, Turkey); and group 4 received midazolam and propofol combination for sedation by choice of the attending anesthesiologist. The anesthetic choice decision was made by the anesthesiologists with respect to the patient's age, comorbidities, and the specifications of the procedure applied. Patients who had epilepsy did not receive ketamine for sedation. The anesthetic choice, airway management, and monitoring were made according to the guideline for monitoring and management of pediatric patients during and after sedation for diagnostic and therapeutic procedures. ${ }^{6,7}$ The anesthetic agents were also chosen according to the procedures and the duration of action of the anesthetic drug as bolus doses. Additional bolus doses of anesthetics were added if necessary (-Table $\mathbf{1}$ ). All patients had oxygen therapy via a nasal cannula during sedation. When the patient's oxygen saturation decreased, the MRI screening was stopped, and the patient was evaluated. If the patient had mechanical obstruction with the tongue obstructing the upper airway because of sedation, an oral airway and jaw suspension maneuver was applied. If the patient had shallow breathing, the patient was ventilated with an Ambumask or intubated if necessary. Furthermore, if the patient had low oxygen saturation due to laryngospasm or bronchospasm, the patient was treated with positive pressure ventilation with an Ambu-mask, inhaled $\beta 2$-agonists, and intravenous steroids.

Study data obtained for analysis included age, weight, gender, ASA classification, diagnosis by service, preexisting comorbidities, type of MRI (i.e., site on the body), preoperative complete blood counts $(\mathrm{CBC})$, preoperative blood urea nitrogen (BUN), creatinine, alanine aminotransferase (ALT), aspartate aminotransferase (AST), peripheral oxygen saturation (SpO2), respiratory rate, heart rate, and anesthesia time. Preoperative CBC, BUN, creatinine, ALT, and AST tests were obtained at the preoperative visit, which usually occurred 1 or 2 days before the MRI scan. CBC measurements were done using Sysmex XN 1000 hematology analyzer (Sysmex America Inc., Illinois, United States), and serum creatinine, BUN, ALT, and AST measurements were done by using commercial kits with Siemens ADVIA Chemistry 2400 auto-analyzer (Siemens Healthineers Diagnostics Ltd, Erlangen, Germany). After the procedure, all patients were monitored in a postanesthesia care unit, and heart rates, respiratory rates, $\mathrm{SpO}$, mean arterial pressure, and complications like itching, nausea, vomiting, and modified Aldrete scores recovery and discharge times were recorded. Patients were discharged from the hospital if the patient's modified Aldrete score was equal to or higher than nine and without any complication for at least 30 minutes. Patients were called by an 
anesthesiologist and questioned about complications, which typically occurred a week after the procedure.

\section{Statistical Analysis}

The patients' demographic data, diagnosis, and type of MRI procedures were analyzed by descriptive statistics. The relations between preoperative laboratory findings, dosages of anesthetic agents, and complications were analyzed by correlation analysis. The association between complications and the type of MRI and anesthetic drugs were analyzed by analysis of variance, and Duncan's test was used to determine the difference between groups. The results are summarized as the $\beta$ coefficient with $95 \%$ confidence intervals and $p$ values. Statistical analysis was performed using the Statistical Package for Social Sciences (SPSS) software program.

\section{Results}

Nine-hundred eighty pediatric patients' records were examined. Three patients were excluded from the study because they were unable to be reached by phone for questioning in regard to any complications experienced a week after the procedure. As such, a total of 977 patients were enrolled in the study. One-hundred fifty-nine patients received midazolam, propofol, and ketamine in group 1. Twenty-four patients received midazolam and ketamine in group 2. One-hundred ninety-nine patients received midazolam and thiopental in group 3, and 595 patients received midazolam and propofol in group 4 for sedation for MRI scanning. There was not any statistical difference between demographic data of the patients between groups ( - Table 2 ). Details of comorbidities of the patients were also given in - Table 2 .

Table 2 Demographic data and comorbidities of the patients

\begin{tabular}{|c|c|c|c|c|}
\hline & $\begin{array}{l}\text { Group } 1 \\
n=159(16.3 \%)\end{array}$ & $\begin{array}{l}\text { Group } 2 \\
n=24(2.5 \%)\end{array}$ & $\begin{array}{l}\text { Group } 3 \\
n=199 \text { (20.4\%) }\end{array}$ & $\begin{array}{l}\text { Group } 4 \\
n=595(60.9 \%)\end{array}$ \\
\hline Gender (F/M) & $59 / 100$ & $16 / 8$ & $98 / 101$ & $247 / 348$ \\
\hline Age groups (y) & $3.26 \pm 2.25$ & $3.48 \pm 3.62$ & $3.77 \pm 3.87$ & $3.79 \pm 3.56$ \\
\hline $0-1$ & 30 & 5 & 42 & 101 \\
\hline $1-7$ & 114 & 18 & 124 & 411 \\
\hline $7-18$ & 15 & 1 & 33 & 81 \\
\hline Weight (kg) & $15.18 \pm 8.81$ & $13.69 \pm 7.45$ & $16.19 \pm 12.28$ & $16.21 \pm 11.27$ \\
\hline ASA classification & 2 & 2 & 2 & 2 \\
\hline 1 & 42 & 0 & 28 & 104 \\
\hline 2 & 107 & 24 & 144 & 449 \\
\hline 3 & 10 & 0 & 27 & 42 \\
\hline Epilepsy & $2(1.3 \%)^{a}$ & $1(4.2 \%)^{b}$ & $110(55.3 \%)^{c}$ & $229(38.5 \%)$ \\
\hline Cerebrovascular event & $1(0.6 \%)$ & 0 & $3(1.5 \%)$ & $1(0.2 \%)$ \\
\hline Intracranial bleeding & $1(0.6 \%)$ & 0 & $8(4.0 \%)$ & $13(2.2 \%)$ \\
\hline Adenoid hyperplasia & $14(8.8 \%)$ & $1(4.2 \%)$ & $15(7.5 \%)$ & $38(6.4 \%)$ \\
\hline Hypothyroidism & $3(1.9 \%)$ & $1(4.2 \%)$ & $5(2.5 \%)$ & $14(2.4 \%)$ \\
\hline Intracranial mass & 7 (4.4\%) & 0 & $24(12.1 \%)$ & $67(11.34 \%)$ \\
\hline Congenital heart disease & $11(6.9 \%)$ & $3(12.5 \%)$ & $13(6.5 \%)$ & $41(6.9 \%)$ \\
\hline Chronic heart failure & 0 & 0 & 0 & $1(0.2 \%)$ \\
\hline Atrial fibrillation & 0 & 0 & 0 & $1(0.2 \%)$ \\
\hline Acute kidney failure & 0 & 0 & 0 & $1(0.2 \%)$ \\
\hline Chronic kidney failure & $1(0.6 \%)$ & 0 & $1(0.5 \%)$ & $3(0.5 \%)$ \\
\hline Syndrome & $14(8.8 \%)$ & $4(16.7 \%)$ & $15(7.5 \%)$ & $50(8.4 \%)$ \\
\hline Genetic & $3(1.9 \%)$ & $1(4.2 \%)$ & $1(0.5 \%)$ & $17(2.9 \%)$ \\
\hline MMR & $22(13.8 \%)$ & $4(16.7 \%)$ & $30(15.1 \%)$ & 77 (12.9\%) \\
\hline Diabetes mellitus & 0 & 0 & 0 & 0 \\
\hline Cerebral palsy & $3(1.9 \%)$ & $1(4.2 \%)$ & $20(10.1 \%)$ & $33(5.5 \%)$ \\
\hline Hypertension & $2(1.3 \%)$ & 0 & 0 & $3(0.5 \%)$ \\
\hline
\end{tabular}

Abbreviations: ASA, American Society of Anesthesiologists; MMR, mental motor retardation.

Patients' genders (female/male), ages (years), weights (kg), ASA risk classifications, and existing comorbidities of the patients are listed as the number $(n)$ of the patients and the percentile (\%) of the patients. Syndrome stands for a coexistence of a congenital syndrome. Genetic stands for coexistence of a genetic abnormality.

Statistical analysis is done by one-sample chi-squared test.

${ }^{\mathrm{a}} p=0.000$ and $p=0.000$ versus group 2 and group 4 .

${ }^{\mathrm{b}} p=0.000$ and $p=0.000$ versus group 3 and group 4 .

${ }^{c} p=0.000$ versus group 4 . 
Table 3 Complications seen after the procedure

\begin{tabular}{|c|c|c|c|c|}
\hline Complications & $\begin{array}{l}\text { Group } 1 \\
n=159(16.3 \%)\end{array}$ & $\begin{array}{l}\text { Group } 2 \\
n=24(2.5 \%)\end{array}$ & $\begin{array}{l}\text { Group } 3 \\
n=199(20.4 \%)\end{array}$ & $\begin{array}{l}\text { Group } 4 \\
n=595(60.9 \%)\end{array}$ \\
\hline Hospitalization & $1(0.7 \%)$ & $1(4.5 \%)$ & $4(2.2 \%)$ & $8(1.4 \%)$ \\
\hline Bronchospasm & $4(2.5 \%)$ & 0 & $6(3 \%)$ & $2(0.3 \%)^{a}$ \\
\hline Bradycardia & $1(0.6 \%)$ & 0 & $1(0.5 \%)$ & 0 \\
\hline Itching & 0 & 0 & 0 & $4(0.7 \%)$ \\
\hline Rash & 0 & 0 & 0 & 0 \\
\hline Nausea & $9(5.7 \%)^{b}$ & 0 & $2(1 \%)$ & $13(2.2 \%)$ \\
\hline Vomiting & $9(5.7 \%)^{c}$ & $0^{d}$ & $2(1 \%)$ & $10(1.7 \%)$ \\
\hline Dizziness & 0 & 0 & $2(1 \%)$ & $2(0.3 \%)$ \\
\hline Headache & $3(1.9 \%)$ & 0 & $2(1 \%)$ & $3(0.5 \%)$ \\
\hline Stomachache & $2(1.3 \%)$ & $1(4.2 \%)$ & $3(1.5 \%)$ & $1(0.7 \%)$ \\
\hline Respiratory depression & $1(0.6 \%)$ & 0 & 0 & $2(0.3 \%)$ \\
\hline \multicolumn{5}{|l|}{ Complications in a week } \\
\hline Nausea & $6(4 \%)$ & $4(17.4 \%)^{e}$ & $6(3.3 \%)$ & $13(2.3 \%)$ \\
\hline Vomiting & $6(4 \%)$ & $5(21.7 \%)^{f}$ & $7(3.8 \%)$ & $12(2.1 \%)$ \\
\hline Rash & $4(2.7 \%)$ & $1(4.3 \%)$ & $1(0.5 \%)$ & $5(0.9 \%)$ \\
\hline Urinary retention & 1 & 0 & 1 & 2 \\
\hline Cardiac arrest & 0 & 0 & 0 & 0 \\
\hline Seizure & $3(2 \%)$ & 0 & $12(6.6 \%)$ & $23(4 \%)$ \\
\hline
\end{tabular}

Complications seen right after the procedure and within a week after the procedure were given as the number $(n)$ of the patients and percentile (\%) of the patients.

Values are given asn (\%). Statistical analyses are done by Fisher's exact test.

${ }^{a} p=0.006$ and $p=0.001$ versus group 1 and group 3 .

${ }^{\mathrm{b}} p=0.02$ versus group 4 .

${ }^{c} p=0.02, p=0.01$ and $p=0.005$ versus group 2, group 3 and group 4 .

${ }^{\mathrm{d}} p=0.002$ versus group 4 .

$\mathrm{e}_{p}=0.007$ versus group 3 and group 4 .

$f_{p}=0.001$ versus group 1 , group 3 , and group 4 .

Epilepsy rates were significantly lower in the patients in groups 1 and 2 than the patients in groups 3 and 4 (- Table 2 ). The patients in group 1 had significantly higher vomiting rates than the patients in group $2(p=0.002)$, group 3 $(p=0.01)$, and group $4(p=0.025)$. The patients in group 4 also had higher vomiting rates than the patients in group 2 $(p=0.002 ;$-Table 3$)$. We observed bronchospasm in the patients in group $1(p=0.006)$ and group $3(p=0.001)$ more than the patients in group 4 ( - Table 3 ). The patients in groups 2 and 3 experienced more nausea than the patients in group 4 within a week after the procedure $(p=0.007$; -Table 3). There was also more vomiting in group 2 when compared with patients in groups 1,3 , and $4(p=0.001$; - Table 3). Procedure time was significantly longer in group 1 than group $4(p<0.001)$, and it was longer in group 4 than group 3 ( $p=0.046 ;-$ Table 4$)$. Recovery times were longer in group $3(p<0.001)$ and group1 $(p=0.023)$ then group 4 (-Table 4). The modified Aldrete scores were similar between groups. One hour after the procedure, respiratory rates were higher in group $1(p<0.001)$ and group 3 $(p=0.006)$ than in group 4 . Two hours after the procedure, respiratory rates were higher in group 1 than group 3 $(p=0.026)$ and group $4(p=0.001 ;$ - Table 4$)$. Mean heart rates were higher in the patients in group 2 than the patients in group $3(p=0.007)$, and mean heart rates were higher in the patients in group $1(p<0.001)$, group $2(p<0.001)$, and group $3(p<0.001)$ then the patients in group $4(-$ Table 4$)$. In the patients in group 2 , no nausea or vomiting was seen right after the procedure. Still, 1 week later, nausea $(p=0.007)$ and vomiting $(p=0.001$ ) ratios were significantly higher than the patients in the other groups. Nausea and vomiting ratios were lower in the patients in group 4 ( - Table 3 ). There were no significant differences between the other parameters. In group 4 , minimum side effects were seen. In group 3 , significantly higher mean platelet volume (MPV) was recorded than group 4 ( - Table 5$)(p<0.001)$. There were not any significant differences between neutrophil-lymphocyte $(\mathrm{N} / \mathrm{L})$ ratios related to the anesthetic drugs used. However, the patients who had nausea $(p=0.012)$ and vomiting $(p=0.012)$ within the week after the procedure had statistically significant lower $\mathrm{N} / \mathrm{L}$ values but had not no difference in MPV values (-Tables 5-6). 
Table 4 Parameters of groups after procedure

\begin{tabular}{|c|c|c|c|c|}
\hline & Group 1 (mean \pm SD) & Group 2 (mean \pm SD) & Group 3 (mean \pm SD) & Group 4 (mean $\pm S D$ ) \\
\hline Procedure times & $19.81 \pm 9.11$ & $22.54 \pm 20.85$ & $17.16 \pm 6.77$ & $17.47 \pm 8.02^{\mathrm{a}}$ \\
\hline Aldrete score & $8.88 \pm 0.5$ & $9.12 \pm 0.5$ & $9.01 \pm 0.3$ & $8.87 \pm 0.7$ \\
\hline Recovery times & $1.86 \pm 0.43$ & $2.04 \pm 0.44$ & $1.90 \pm 0.33$ & $1.80 \pm 0.34^{\mathrm{b}}$ \\
\hline $\begin{array}{l}\text { Respiratory rates } 1 \text { hour } \\
\text { later }\end{array}$ & $26.26 \pm 1.58$ & $25.54 \pm 2.5$ & $26.08 \pm 1.87$ & $25.42 \pm 2.18^{c}$ \\
\hline $\begin{array}{l}\text { Respiratory rates } 2 \text { hours } \\
\text { later }\end{array}$ & $25.26 \pm 1.71^{d}$ & $24.58 \pm 2.04$ & $24.70 \pm 1.77$ & $24.53 \pm 3.67$ \\
\hline Heart rates 1 hour later & $112.78 \pm 14.82$ & $123.71 \pm 18.35^{\mathrm{e}}$ & $110.13 \pm 18.23$ & $103.47 \pm 16.8^{f}$ \\
\hline Heart rates 2 hours later & $112.31 \pm 14.28$ & $118.42 \pm 17.58$ & $109.05 \pm 15.87$ & $104.63 \pm 16.11^{g}$ \\
\hline SpO2 1 hour later & $98.77 \pm 1.42$ & $98.63 \pm 1.47$ & $98.55 \pm 1.52$ & $98.66 \pm 1.7$ \\
\hline SpO2 2 hours later & $99.43 \pm 0.98$ & $99.13 \pm 0.95$ & $99.43 \pm 0.97$ & $99.34 \pm 1.12$ \\
\hline $\begin{array}{l}\text { Preoperative } \mathrm{Hb} \\
\text { value }(\mathrm{mg} / \mathrm{dL})\end{array}$ & $11.80 \pm 1.29$ & $12.48 \pm 1.41$ & $11.92 \pm 1.24$ & $12.36 \pm 1.38$ \\
\hline $\begin{array}{l}\text { Preoperative hemathocrit } \\
\text { value (\%) }\end{array}$ & $35.65 \pm 3.70$ & $37.96 \pm 4.12$ & $35.88 \pm 3.78$ & $35.87 \pm 3.89$ \\
\hline $\begin{array}{l}\text { Preoperative WBC } \\
\left(1,000 \mathrm{~mm}^{3}\right)\end{array}$ & $9497.04 \pm 3688.06$ & $9665.22 \pm 2715.21$ & $9195.78 \pm 3207.8$ & $9030.21 \pm 3260.94$ \\
\hline $\begin{array}{l}\text { Preoperative neutrophil } \\
\left(1,000 \mathrm{~mm}^{3}\right)\end{array}$ & $3955.28 \pm 2440.93$ & $3926.09 \pm 2085.28$ & $3511.41 \pm 1738.7$ & $3636.98 \pm 1924.91$ \\
\hline $\begin{array}{l}\text { Preoperative lymphocyte } \\
\left(1,000 \mathrm{~mm}^{3}\right)\end{array}$ & $4328.93 \pm 2048.51$ & $4556.52 \pm 1598.81$ & $4458.28 \pm 2178.8$ & $4288.65 \pm 2101.70$ \\
\hline $\begin{array}{l}\text { Preoperative } \\
\text { neutrophil (\%) }\end{array}$ & $40.55 \pm 14.51$ & $38.70 \pm 14.34$ & $38.42 \pm 14.11$ & $39.79 \pm 14.49$ \\
\hline $\begin{array}{l}\text { Preoperative } \\
\text { lymphocyte (\%) }\end{array}$ & $45.33 \pm 13.14$ & $46 \pm 12.88$ & $47.54 \pm 13.18$ & $46.59 \pm 13.82$ \\
\hline $\begin{array}{l}\text { Preoperative platelet } \\
\left(1,000 \mathrm{~mm}^{3}\right)\end{array}$ & $377.83 \pm 126.76$ & $380.17 \pm 114.60$ & $362.16 \pm 119.49$ & $346.99 \pm 106.69$ \\
\hline Preoperative BUN (mg/dL) & $11.71 \pm 4.68$ & $9.75 \pm 3.20$ & $11.13 \pm 5.91$ & $11.16 \pm 4.26$ \\
\hline $\begin{array}{l}\text { Preoperative creatinine } \\
(\mathrm{mg} / \mathrm{dL} \text { ) }\end{array}$ & $0.29 \pm 0.11$ & $0.20 \pm 0.08$ & $0.31 \pm 0.16$ & $0.30 \pm 0.23$ \\
\hline Preoperative ALT (U/L) & $26.26 \pm 45.77$ & $18.75 \pm 2.75$ & $23.70 \pm 15.70$ & $20.19 \pm 11.62$ \\
\hline Preoperative AST (U/L) & $37.32 \pm 45.68$ & $33.0 \pm 8.76$ & $37.73 \pm 16.54$ & $29.60 \pm 15.69$ \\
\hline
\end{tabular}

Abbreviations: ALT, alanine aminotransferase; AST, aspartate aminotransferase; BUN, blood urea nitrogen; MRI, magnetic resonance imaging; SD, standard deviation; $\mathrm{SpO}_{2}$, peripheral oxygen saturation; WBC, white blood cell.

Total MRI scan times, Aldrete scores before the patients were discharged, recovery times; time spent after the MRI scan until the patients are discharged, respiratory rates 1 and 2 hours after the MRI scan and heart rates 1 and 2 hours after the MRI scan were given as mean \pm SD.

Values are given as mean \pm SD Statistical analysis was done by Kruskal-Wallis one way analysis of variance on ranks with multiple comparisons by Bonferroni correction.

${ }^{\mathrm{a}} p=0.046$ and $p=0.000$ versus group 3 and group 1 .

${ }^{\mathrm{b}} p=0.000$ and $p=0.023$ versus group 3 and group 1 .

${ }^{c} p=0.000$ and $p=0.006$ versus group 1 and group 3 .

${ }^{d} p=0.026$ and $p=0.001$ versus group 3 and group 4 .

$\mathrm{e}_{p}=0.007$ versus group 3 .

${ }^{f} p=0.000, p=0.000$ and $p=0.000$ versus group 1 , group 2 , and group 3 .

${ }^{g} p=0.000, p=0.000$ and $p=0.000$ versus group 1 , group 2 , and group 3 .

\section{Discussion}

The present study retrospectively reviewed anesthetic choices used for sedation during MRI for pediatric patients. We aimed to determine complications arising from these processes in our institution. To this extent, patients' records were reviewed for anesthetic choices, anesthetic environ- ment, complications after the procedure, and complications developed a week after the procedure. It was determined that in our institution, ketamine and propofol combination was used for most of the patients. Still, the midazolam and propofol combination has the lowest complication ratio, and $\mathrm{N} / \mathrm{L}$ ratio rates were lower in patients with nausea and vomiting seen in a week after the procedure. 
e190 Sedation of Pedatric Patients during MRI Aycan et al.

Table $5 \mathrm{~N} / \mathrm{L}$ ratios and MPV values before the procedure

\begin{tabular}{|l|l|l|l|l|}
\hline & Group 1 & Group 2 & Group 3 & Group 4 \\
\hline N/L & $1.09 \pm 0.75$ & $1.01 \pm 0.72$ & $1.04 \pm 1.27$ & $1.10 \pm 1.03$ \\
\hline N/L percentile & $1.09 \pm 0.75$ & $0.99 \pm 0.70$ & $1.05 \pm 1.35$ & $1.09 \pm 0.98$ \\
\hline MPV & $7.71 \pm 0.85$ & $7.67 \pm 1.04$ & $7.94 \pm 0.92^{\text {a }}$ & $7.61 \pm 1.02$ \\
\hline
\end{tabular}

Abbreviations: CBC, complete blood count; MPV, mean platelet volume; N/L, neutrophil-lymphocyte; SD, standard deviation.

Neutrophil lymphocyte ratios calculated from preoperative $C B C$ test and percentile of neutrophil and lymphocyte again calculated from CBC test and mean platelet volume values are given as mean \pm SD of the groups.

Values are mean \pm SD.

${ }^{\mathrm{a}} p=0.000$ versus group 4 . Statistical analysis was done by Tamhane test and multiple comparisons by Welch test.

Table 6 Relationship between nausea and vomiting and preoperative N/L percentile ratios and MPV

\begin{tabular}{|l|l|l|l|}
\hline & Total number & N/L percentile (mean \pm SD) & MPV (mean \pm SD) \\
\hline Nausea not seen after procedure & 941 & $1.08 \pm 1.04$ & $7.69 \pm 0.99$ \\
\hline Nausea seen after procedure & 24 & $1.12 \pm 0.76$ & $7.80 \pm 0.84$ \\
\hline Vomiting not seen after procedure & 944 & $1.08 \pm 1.03$ & $7.68 \pm 0.98$ \\
\hline Vomiting seen after procedure & 21 & $1.15 \pm 0.80$ & $7.67 \pm 0.82$ \\
\hline Nausea not seen in a week & 896 & $1.07 \pm 0.89^{\text {a }}$ & $7.67 \pm 0.98$ \\
\hline Nausea seen in a week & 27 & $0.73 \pm 0.55$ & $7.79 \pm 0.97$ \\
\hline Vomiting not seen in a week & 892 & $1.07 \pm 0.89^{\text {b }}$ & $7.67 \pm 0.98$ \\
\hline Vomiting seen in a week & 30 & $0.76 \pm 0.60$ & $7.91 \pm 1.13$ \\
\hline
\end{tabular}

Abbreviations: MPV, mean platelet volume; N/L, neutrophil-lymphocyte; SD, standard deviation.

Relationship between nausea and vomiting seen in all patients and preoperative calculated neutrophil lymphocyte percentile ratios and mean platelet volume values were given as mean \pm SD.

a $p=0.012$ versus nausea not seen in a week.

${ }^{\mathrm{b}} \mathrm{p}=0.012$ versus vomiting not seen in a week.

An MRI scan has become the preferred diagnostic procedure for many conditions because it is a noninvasive, radiation-free diagnostic procedure. It is a lengthy and noisy procedure, however, and requires immobility. Also, monitorization is a problem because classic monitors cannot be used in a magnetic field. There are particular types of equipment for MRI rooms. Our institution lacks this special equipment, so we monitor the patients with pulse oximetry outside the MRI room, with the pulse-oximetry probe attached to the patient with an extension line through a hole at the window of the MRI room. Another problem in an MRI environment is that metal objects can become projectiles, so the patient must not have any metal objects on them in the MRI room. Sedation or anesthesia is required when the child is uncooperative, or the child has to be at rest during the procedure. The anesthetist must provide a motionless patient during the procedure without interfering with the patient's safety. Access to the patient is limited during an MRI. To prevent the side effects of anesthetic drugs, combinations of anesthetic drugs are used. Most children who need MRI have some comorbidities such as neurological diseases, vascular malformation, or oncological tumor growth. In this group of patients, epilepsy, intellectual disability, or spasticity is common. ${ }^{8,9}$ The anesthetist must consider these conditions when managing sedation or anesthesia for MRI in children.
Metals can interfere with the image quality of the MRI and can cause side effects in the patient like a warming sensation. Also, metal devices such as pacemakers malfunction and get damaged by the magnetic field. As such, some specific considerations must be given for the design of the anesthesia workstation in an MRI environment. The workstation must also contain a ventilator, anesthetic gas measurement, capnography, pulse oximetry, electrocardiogram, blood pressure, and respiratory frequency monitors. The ventilator used for pediatric patients must contain compliance compensation. Finally, it must be kept in mind that if an emergency stop is needed, the result is time and cost-consuming. In the end, the primary goals to be achieved are maximum patient safety, successful scanning, and paramount image quality. $^{2}$

According to the American Academy of Pediatrics, sedation in children is defined in four steps: anxiolysis, conscious sedation, deep sedation, and anesthesia. The main goal of sedation for diagnostic and therapeutic procedures in the pediatric patient is to ensure the patient's safety and prevent the pain and discomfort of the patient. At the same time, the patient's movement must be avoided to ensure the quality of the images being obtained. Finally, the patient must be safely discharged at the end of the procedure. ${ }^{2}$

Concerning children and MRI, deep sedation is required for examination in most cases because of noise and the 
narrowness of the bore. Stopping an MRI scan is expensive and ineffective; thus, the failure rate must be minimized. Preoperative fasting is the same as general anesthesia. During the procedure, intravenous access and monitoring are also mandatory, and an experienced anesthetist and emergency equipment must be nearby. ${ }^{2}$ It must be kept in mind that disabled children are three times more prone to hypoxia under sedation. ${ }^{9}$ The patient has to be under the supervision of an experienced anesthetist because of the limited access and view during the MRI scan. If anything goes wrong during the MRI scan, such as hypoventilation, the management of the patient must have been practiced previously by the team, as interfering with such a patient can be challenging and time-consuming. Also, newborns are known to be vulnerable to desaturation, and bradycardia occurs immediately after desaturation. An anesthesiologist must consider these conditions when managing proper anesthesia and monitoring for pediatric patients during MRI, which must be kept in mind when choosing a suitable anesthetic procedure and monitoring pediatric patients. ${ }^{2}$

We chose anesthetic drugs according to the patient's comorbidities and procedure time. Epilepsy rates were lower in the patients in groups 1 and 2 because we do not prefer ketamine for patients with epilepsy. Midazolam and ketamine combination was preferred for more lengthy procedures since midazolam has a longer duration of action. Midazolam and pentothal combination was preferred for shorter procedures since thiopental has a shorter duration of action. None of our patients had low SpO2 levels or bradycardia. Since ketamine increases heart rate, tachycardia was recorded in the midazolam and ketamine groups. ${ }^{10}$ After 1 hour from the procedure, respiration rates were lower with midazolam and ketamine, then ketamine and propofol combination, because midazolam's duration of action is more prolonged than propofol. ${ }^{10}$ Again, respiration rates with midazolam and thiopental were higher than midazolam and propofol because propofol's duration of action is more prolonged than thiopental. ${ }^{10}$ Despite statistically significant differences in respiratory rates and heart rates between groups, these differences were not clinically significant. None of the patients had respiratory complications during the perioperative period. The SpO2 levels did not differ between groups. Mallory et al found in their multicenter study that propofol provides more efficient and effective sedation than pentobarbital for children undergoing MRI. ${ }^{11}$ Pediatric sedation research consortium reported, in a study which was conducted on 49,836 children at 37 centers, that according to these findings, propofol is a good anesthetic choice without serious side effects when applied by a wellorganized anesthesia team. ${ }^{12}$ The data indicate that propofol sedation/anesthesia is unlikely to yield severe adverse outcomes in a collection of institutions with highly motivated and organized sedation/anesthesia services. ${ }^{12}$ We also chose propofol combinations for most of our patients. Schmitz et al reported that ketamine at induction with a reduced propofol infusion rate leads to faster postanesthetic recovery. ${ }^{13} \mathrm{We}$ did not find any differences between the groups' recovery times, but we also found that we mainly chose ketamine with propofol combination. Only a small number of the patients received ketamine and midazolam combination. In the midazolam and ketamine group, nausea and vomiting were not seen right after the procedure, but the nausea and vomiting ratio was highest during the week after the procedure. The patients who experienced less nausea and vomiting had a lower $\mathrm{N} / \mathrm{L}$ ratio.

The N/L ratio is a well-known inflammation marker. ${ }^{14-19}$ Inflammation and nausea and vomiting seem to correlate. ${ }^{14}$ It is well known that dexamethasone is an antiemetic agent. $^{20,21}$ Its estimated mechanism of action is preventing activation of the chemoreceptor trigger zone by activation of glucocorticoid receptors found within the bilateral solitary tract nucleus and area postrema of the brain stem, implicated as a central emetogenic mediator. ${ }^{22}$ Another theory centers around the anti-inflammatory properties of dexamethasone, which may help reduce inflammatory reaction's leading parasympathetically driven stimulation of the chemoreceptor trigger zone. ${ }^{23,24} \mathrm{MPV}$ is another marker of an inflammatory response, but it is a weak marker. ${ }^{25,26}$ In our study, we also did not find any correlation between nausea and vomiting and MPV values. Only in the third group, we discovered that MPV values were higher than the other groups. To our knowledge, no studies have shown the effects of anesthetic drugs on MPV values. Further investigations can be planned to investigate the relation between anesthetic drugs and MPV values.

Our study has some limitations; as this study was a retrospective study, the number of patients of the groups was not equal. Furthermore, comorbidities like epilepsy were not an equal number between groups. These situations cause some difficulties in statistical analyses.

\section{Conclusion}

All four anesthetic combinations can be used safely during MRI for children. Minimum side effects were achieved with midazolam and propofol combination. Anesthetists must choose the proper anesthetic technique according to the procedure's time and the patient's comorbidities. The essential issue is close monitoring both during and after the procedure. Notably, midazolam and propofol combination seems to have a minimum complication ratio.

Conflict of Interest

None declared.

\section{References}

1 MacManus B. Trained nurses can provide safe and effective sedation of MRI in pediatric patients. Can J Anaesth 2000;47 (03):197-200

2 Uentrop LS, Goepfert MS. Anaesthesia or sedation for MRI in children. Curr Opin Anaesthesiol 2010;23(04):513-517

3 Meléndez JC, McCrank E. Anxiety-related reactions associated with magnetic resonance imaging examinations. JAMA 1993;270 (06):745-747

4 Perez M, Cuscaden C, Somers JF, et al. Easing anxiety in preparation for pediatric magnetic resonance imaging: a pilot study using animal-assisted therapy. Pediatr Radiol 2019;49(08):1000-1009 
5 Morgan \& Mikhail's Clinical Anesthesiology. 5th edition New York: Lange; 2017:175-188

6 Coté CJ, Wilson SAmerican Academy of Pediatrics American Academy of Pediatric Dentistry. Guidelines for monitoring and management of pediatric patients before, during, and after sedation for diagnostic and therapeutic procedures: update 2016 Pediatrics 2016;138(01):e20161212

7 Coté CJ, Wilson SAmerican Academy of Pediatrics American Academy of Pediatric Dentistry Work Group on Sedation. Guidelines for monitoring and management of pediatric patients during and after sedation for diagnostic and therapeutic procedures: an update. Pediatrics 2006;118(06):2587-2602

8 Funk W, Hörauf K, Held P, Taeger K. [Anesthesia for magnetic resonance tomography in neonates, infants and young children]. Radiologe 1997;37(02):159-164

9 Kannikeswaran N, Mahajan PV, Sethuraman U, Groebe A, Chen X. Sedation medication received and adverse events related to sedation for brain MRI in children with and without developmental disabilities. Paediatr Anaesth 2009;19(03):250-256

10 Clinical anesthesiology. 5th edition Lange, New York 2013: 175-187

11 Mallory MD, Baxter AL, Kost SIPediatric Sedation Research Consortium. Propofol vs pentobarbital for sedation of children undergoing magnetic resonance imaging: results from the Pediatric Sedation Research Consortium. Paediatr Anaesth 2009;19(06):601-611

12 Cravero JP, Beach ML, Blike GT, Gallagher SM, Hertzog JHPediatric Sedation Research Consortium. The incidence and nature of adverse events during pediatric sedation/anesthesia with propofol for procedures outside the operating room: a report from the Pediatric Sedation Research Consortium. Anesth Analg 2009;108 (03):795-804

13 Schmitz A, Weiss M, Kellenberger C, et al. Sedation for magnetic resonance imaging using propofol with or without ketamine at induction in pediatrics-a prospective randomized doubleblinded study. Paediatr Anaesth 2018;28(03):264-274

14 Yıldız AA, Demirel I, Bolat E, et al. The relationship between the preoperative neutrophil to lymphocyte ratio and postoperative nausea and vomiting in patients undergoing septorhinoplasty surgery. Aesthetic Plast Surg 2019;43(03):861-865
15 Liu CC, Ko HJ, Liu WS, et al. Neutrophil-to-lymphocyte ratio as a predictive marker of metabolic syndrome. Medicine (Baltimore) 2019;98(43):e17537. Doi: 10.1097/MD.0000000000017537

16 Meng LB, Yu ZM, Guo P, et al. Neutrophils and neutrophillymphocyte ratio: Inflammatory markers associated with intimal-media thickness of atherosclerosis. Thromb Res 2018; 170:45-52

17 Bahadır A, Baltacı D, TürkerY, et al. Is the neutrophil-to-lymphocyte ratio indicative of inflammatory state in patients with obesity and metabolic syndrome? Anatol J Cardiol 2015;15(10):816-822

18 Guthrie GJK, Charles KA, Roxburgh CSD, Horgan PG, McMillan DC, Clarke SJ. The systemic inflammation-based neutrophil-lymphocyte ratio: experience in patients with cancer. Crit Rev Oncol Hematol 2013;88(01):218-230

19 Forget P, Khalifa C, Defour JP, Latinne D, Van Pel MC, De Kock M. What is the normal value of the neutrophil-to-lymphocyte ratio? BMC Res Notes 2017;10(01):12

20 Tzeng JI, Wang JJ, Ho ST, Tang CS, Liu YC, Lee SC. Dexamethasone for prophylaxis of nausea and vomiting after epidural morphine for post-Caesarean section analgesia: comparison of droperidol and saline. Br J Anaesth 2000;85(06):865-868

21 Subramaniam B, Madan R, Sadhasivam S, et al. Dexamethasone is a cost-effective alternative to ondansetron in preventing PONV after paediatric strabismus repair. Br J Anaesth 2001;86(01):84-89

22 Gan TJ, Diemunsch P, Habib AS, et al; Society for Ambulatory Anesthesia. Consensus guidelines for the management of postoperative nausea and vomiting. Anesth Analg 2014;118(01):85-113

23 Ho CM, Wu HL, Ho ST, Wang JJ. Dexamethasone prevents postoperative nausea and vomiting: benefit versus risk. Acta Anaesthesiol Taiwan 2011;49(03):100-104

24 Urits I, Orhurhu V, Jones MR, et al. Postoperative nausea and vomiting in paediatric anaesthesia. Turk J Anaesthesiol Reanim 2020;48(02):88-95

25 Demirer Z, Karademir I, Uslu AU, Güragac A, Aksu Y. The relationship between inflammation and mean platelet volume in varicocele pathophysiology. Rev Int Androl 2018;16(04):137-142

26 Gokdemir MT, Gokdemir GS, Taş M The association between mean platelet volume and inflammation in geriatric patients with emergency hypertension. Turk J Emerg Med 2018;19(01):16-20 